\title{
Estudio de la influencia de los medios con presencia de sulfatos en hormigones con cementos sulforresistentes y adiciones minerales. Parte 2. Hormigones expuestos a sulfato magnésico $\left(\mathrm{MgSO}_{4}\right)$
}

\author{
The influence of sulfuric environments on concretes elaborated with sulfate resistant cements and \\ mineral admixtures. Part 2: Concrete exposed to Magnesium Sulfate $\left(\mathrm{MgSO}_{4}\right)$
}

Bernal Camacho, J. (Autor Principal y Autor Oficial de Contacto) jesusmanuel.bernal.camacho@alumnos.upm.es Universidad Politécnica de Madrid

Departamento of Civil Engineering: Construction C/Profesor Aranguren, sn, 28040 Madrid, Spain Tel. 0034-913366721

Mahmoud Abdelkader, S.

Universidad Politécnica de Madrid

Departamento of Civil Engineering: Construction

safwat.mahmoud@upm.es
Reyes Pozo, E.

Universidad Politécnica de Madrid

Departamento of Civil Engineering: Construction

ereyes@caminos.upm.es

Monteagudo Viera, S.

Universidad Politécnica de Madrid

Departamento of Civil Engineering: Construction

sm.monteagudo@alumnos.upm.es

\begin{abstract}
Resumen
El presente trabajo estudia la resistencia de hormigones al ataque de sulfatos provenientes de sulfato magnésico $\left(\mathrm{MgSO}_{4}\right)$ y compara estos valores con resultados previos de los mismos hormigones atacados con sulfato sódico $\left(\mathrm{Na}_{2} \mathrm{SO}_{4}\right)$. De esta manera se estudia la interacción de catión que acompaña al ion sulfato durante su afectación a la matriz cementicia. Para lo anterior, se diseñaron cuatro dosificaciones empleando cementos sulforresistentes y adiciones minerales (humo de sílice, ceniza volante y escoria de alto horno). Los hormigones se sumergieron, por distintos periodos de tiempo, en disolución de sulfato magnésico $\left(\mathrm{MgSO}_{4}\right)$ de concentración $1 \mathrm{M}$, para después realizarles ensayos mecánicos y a nivel microestructural. Los valores obtenidos se compararon con los obtenidos en el hormigón de referencia curado en hidróxido cálcico. El hormigón con escoria de alto horno presentó el mejor comportamiento frente a $\mathrm{MgSO}_{4}$, siendo las mezclas de humo de sílice y ceniza volante las más susceptibles. La resistencia del hormigón con escoria se atribuye a las características de los silicatos hidratados formados durante la hidratación, los cuales incorporan aluminio en las cadenas impidiendo su descomposición ante un ataque por magnesio. El medio con sulfato magnésico mostro una mayor agresividad que el medio con sulfato sódico.
\end{abstract}

Código: 0147

Fecha de Aceptación: 1 de diciembre de 2013

The present work studies the resistant of the concrete against magnesium sulfate $\left(\mathrm{MgSO}_{4}\right)$ and compare the results with values obtained previously of the same concretes exposed to sodium sulfate $\left(\mathrm{Na}_{2} \mathrm{SO}_{4}\right)$. Thus, it is possible analyze the influence of the cation type. To that end, four different concrete mixes were made with sulfur resistant cement and mineral admixtures (silica fume, fly ash and blast furnace slag). The concretes were submerged for different period in magnesium sulfate $\left(\mathrm{MgSO}_{4}\right)$. After that, different tests were carried out to define mechanical and microstructural properties. The results obtained were compared with reference values of concretes cured in calcium hydroxide $\left[\mathrm{Ca}(\mathrm{OH})_{2}\right]$. According to the results, the concrete with blast furnace slag presented the best behavior front $\mathrm{MgSO}_{4}$, meanwhile the concretes with silica fume and fly ash were the most susceptible. The resistance of the concrete with blast furnace slag could be attributed to the characteristics of the hydrated silicates formed during the hydration time, which include aluminum in the chemical chain that hinder its chemical decomposition during the attack of magnesium. The magnesium sulfate solution was most aggressive than sodium sulfate solution.

Keywords: Concrete; Sulfate resistant cement; Sodium sulfate; Magnesium sulfate; Mineral admixtures

\section{Introducción}

En la primera parte del presente trabajo de investigación (Bernal et al., 2013) se analizó la influencia en el hormigón de sulfatos provenientes de una solución de sulfato sódico $\left(\mathrm{Na}_{2} \mathrm{SO}_{4}\right)$ de concentración 1 molar. Los valores obtenidos mostraron un bajo grado de agresividad de los sulfatos frente a los hormigones e inclusive se identificaron mejoras en características mecánicas y de durabilidad para algunas mezclas. Por lo anterior y con el afán de ampliar la investigación, se llevó a cabo una campaña experimental donde se emplearon las mismas dosificaciones de los hormigones cambiando únicamente el medio agresivo por una solución de sulfato magnésico $\left(\mathrm{MgSO}_{4}\right)$ de concentración 1 molar.

En la presente investigación se estudia el comportamiento de distintas mezclas de hormigón frente a sulfato magnésico $\left(\mathrm{MgSO}_{4}\right)$. Los resultados obtenidos se contrastan con los valores de un hormigón de referencia curado en hidróxido cálcico. Además, empleando resultados obtenidos previamente de hormigones expuestos a sulfato sódico $\left(\mathrm{Na}_{2} \mathrm{SO}_{4}\right)$, se analiza el avance diferencial de sulfatos en los distintos medios y la influencia del catión presente, así como los cambios en la microestructura a distintas edades. El estudio experimental se centró en cuatro hormigones, un hormigón patrón elaborado con cemento sulforresistente CEM I 42,5 R/SR (UNE-EN 1971:2000) y tres utilizando adiciones minerales. Para la mezcla con escoria de alto horno se empleó cemento sulforresistente CEM III/B 42,5 L/SR (UNE-EN 197-1:2000). En las dos dosificaciones restantes se sustituyó parcialmente el primer cemento, empleando adiciones de humo de sílice y ceniza volante en un $10 \%$ y $20 \%$, respectivamente. 


\section{Estado del arte}

Diversos estudios identifican al sulfato sódico $\left(\mathrm{Na}_{2} \mathrm{SO}_{4}\right)$ y el sulfato magnésico $\left(\mathrm{MgSO}_{4}\right)$ como los principales compuestos químicos con sulfatos en disolución en contacto con el hormigón. El primero reacciona principalmente con el hidróxido cálcico para formar sulfato cálcico (yeso), que subsecuentemente con presencia de aluminato tricálcico $\left(C_{3} A\right)$ formaran monosulfoaluminatos y etringita. Mientras el sulfato magnésico reacciona principalmente con los productos hidratados del cemento formando yeso e hidróxido de magnesio (brucita) (Neville, 2004). La aparición de brucita tiende a reducir la permeabilidad del hormigón protegiendo las capas internas esto puede llegar a reducir la estabilidad de los C-S-H en la pasta del cemento provocando una reducción de la resistencia a compresión (Shah \& Hookham, 1998).

La velocidad de ataque de los sulfatos depende de la concentración de estos en la solución, los efectos llegan a tener importancia en concentraciones por encima $1 \%$ y $0.5 \%$, para sulfato sódico y sulfato magnésico, respectivamente (Eglinton, 1998). La vía de acción principal del sulfato depende del tipo de catión que lo acompaña (Al-moudi et al., 1995). El medio agresivo con sulfato magnésico está considerado de mayor grado de agresividad que con sulfato sódico, debido al descenso del pH de la solución de los poros en la pasta de cemento hidratada por la formación de brucita (Metha, 1992).

\section{Materiales empleados y métodos}

\section{Materiales}

Se diseñaron cuatro mezclas de hormigón empleando dos tipos de cementos sulforresistentes, CEM I 42,5 R/SR y CEM III/B 42,5 L/SR. Se dosificaron adiciones de humo de sílice (HS) y ceniza volante (CV), como sustitución parcial del primero de los cementos, empleando valores de 2 y 0,3 como coeficientes de eficacia (K), respectivamente. La relación agua/material cementante se estableció en 0,45 para todas las mezclas. Se emplearon áridos gruesos de naturaleza caliza procedentes de machaqueo con tamaño 4/20 mm y arena silícea de río con tamaño $0 / 4 \mathrm{~mm}$. Además, se utilizó aditivo superplastificante (SIKA Viscocrete 3425) para mejorar la trabajabilidad, controlando los valores de asentamiento. La Tabla 1 muestra las dosificaciones definidas para la elaboración de las mezclas. La composición química y propiedades físicas de los materiales cementicios se presentan en la Tabla 2.

\begin{tabular}{|c|c|c|c|c|}
\hline Material & CPRS & CPRS+HS & CPRS+CV & EHA \\
\hline Cemento & 380 & 304 & 357 & 380 \\
\hline Humo de silice & 0 & 38 & 0 & 0 \\
\hline Ceniza volante & 0 & 0 & 76 & 0 \\
\hline Agua & 171 & 154 & 194 & 171 \\
\hline Grava & 1022 & 1067 & 966 & 1022 \\
\hline Arena & 787 & 800 & 770 & 787 \\
\hline SP (\%) & 0,97 & 1,8 & 0,7 & 1,3 \\
\hline
\end{tabular}

El hormigón se fabricó siguiendo el procedimiento descrito en la norma UNE-EN 12390-2:2001 (UNE-EN 12390-2,2001), a una temperatura comprendida entre 20-25ㄷ. Se utilizó una amasadora de eje vertical, con cuba fija y paletas giratorias con movimiento planetario con capacidad de 100 litros. Para cubrir la totalidad del programa experimental establecido, se elaboraron probetas cilíndricas de $\varnothing=150 \mathrm{~mm}$ y $\mathrm{h}=300 \mathrm{~mm}$, además de probetas de $\varnothing=100 \mathrm{~mm}$ y $\mathrm{h}=200 \mathrm{~mm}$.

\section{Métodos empleados}

El hormigón en estado endurecido se ensayó en condiciones normales curado en una disolución saturada de hidróxido calcio, estos valores se tomaron como referencia para comparar los resultados obtenidos de los hormigones expuestos al medio agresivo. Los ensayos consistieron en la medida de propiedades mecánicas, capacidad de transporte de agentes agresivos y propiedades microestructurales. El estudio de las propiedades mecánicas se centró en ensayos de resistencia a compresión (UNE-EN 12390-2:2001). Para evaluar la capacidad de transporte de los hormigones las muestras fueron sometidas a ensayos de difusión no estacionaria. Los ensayos se realizaron según la norma (UNE-EN 196-2:2006). La caracterización microestructural consistió en ensayos de porosimetría por intrusión de mercurio (PIM), análisis térmicos (termogravimétricos y térmico diferencial) y ensayos de difracción por Rayos-X.

\begin{tabular}{|c|c|c|c|c|}
\hline Parámetro & $\begin{array}{c}\text { CEM I } \\
42.5 \mathrm{R} / \mathrm{SR}\end{array}$ & $\begin{array}{l}\text { CEM III/B } \\
42,5 \text { L/SR }\end{array}$ & HS & CV \\
\hline $\mathrm{SiO}_{2}$ & 21.58 & 26.70 & 85.0 & 40.66 \\
\hline $\mathrm{Al}_{2} \mathrm{O}_{3}$ & 3.48 & 7.40 & -- & 30.02 \\
\hline $\mathrm{Fe}_{2} \mathrm{O}_{3}$ & 4.78 & 1.80 & -- & 19.93 \\
\hline $\mathrm{CaO}$ & 67.64 & 50.20 & 1.0 & 8.09 \\
\hline MgO & 1.00 & 6.80 & -- & 1.70 \\
\hline $\mathrm{Na}_{2} \mathrm{O}$ & -- & 0.23 & 1.5 & 0.22 \\
\hline $\mathrm{K}_{2} \mathrm{O}$ & -- & 0.78 & -- & 1.13 \\
\hline $\mathrm{SO}_{3}$ & 3.3 & 3.03 & 2.0 & 0.85 \\
\hline $\mathrm{Cl}^{-}$ & 0.01 & 0.03 & 0.1 & 0 \\
\hline $\begin{array}{l}\text { Pérdida al } \\
\text { fuego }\end{array}$ & -- & 1.50 & -- & 1.14 \\
\hline $\begin{array}{l}\text { Perdido por } \\
\text { calcinación }\end{array}$ & 3.16 & -- & 4.0 & -- \\
\hline $\begin{array}{l}\text { Residuo } \\
\text { Insoluble }\end{array}$ & 1.25 & 1.48 & -- & -- \\
\hline
\end{tabular}

Resultados y discusiones

Caracterización del hormigón de referencia en estado endurecido

Los hormigones empleados en los ensayos de caracterización se curaron dentro de una solución saturada de $\mathrm{Ca}(\mathrm{OH})_{2}$ a $20-25$ 으 de temperatura. Para el estudio del hormigón en estado endurecido se llevaron a cabo ensayos de caracterización mecánica y microestructural, que se han tomado como valores de referencia al compararlos con los hormigones expuestos al medio agresivo. La caracterización mecánica se basó en ensayos de resistencia a compresión a distintas edades para estudiar su evolución y la influencia de las adiciones empleadas. Las propiedades a nivel microestructural se determinaron mediante ensayos de porosimetría por intrusión de mercurio, análisis térmico diferencial y difracción de rayos $\mathrm{X}$. 
Mediante estos ensayos se determinaron valores de porosidad y distribución de tamaño de poros, además de identificar los productos de la hidratación del cemento y de las reacciones puzolánicas de las adiciones. Los resultados obtenidos de la caracterización de los hormigones de referencia han sido expuestos en el artículo "Estudio de la influencia de los medios con presencia de sulfatos en hormigones con cementos sulforresistentes y adiciones minerales. Parte 1. Hormigones expuestos a sulfato sódico $\left(\mathrm{Na}_{2} \mathrm{SO}_{4}\right)$ " (Bernal et al., 2013), donde pueden ser consultados.

Exposición de los hormigones a sulfato magnésico $\left(\mathrm{MgSO}_{4}\right)$

Las muestras de hormigón fueron sumergidas en solución de sulfato magnésico $\left(\mathrm{MgSO}_{4}\right)$ preparadas en el laboratorio. La concentración de la disolución fue de 1 molar, superior a la de los medios naturales con el fin de acelerar el proceso de degradación. Durante el periodo de exposición se controló la concentración de la disolución para mantenerla constante a lo largo del ensayo. Para este ensayo se utilizaron probetas de $\varnothing=100 \mathrm{~mm}$ y $200 \mathrm{~mm}$ de altura, a las que se realizó el corte de una locha de $10 \mathrm{~mm}$ de la parte superior de las probetas. La superficie cortada fue la expuesta al medio agresivo. El resto de superficies se recubrieron con resina hasta alcanzar $1 \mathrm{~mm}$ de espesor para garantizar la penetración unidireccional del agresivo. La Figura 1 muestra la probeta previamente a ser sumergida en el medio agresivo.

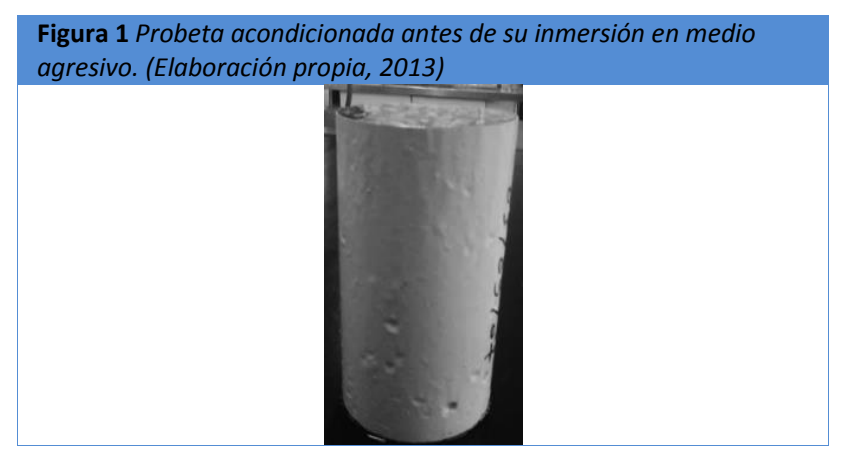

El sulfato magnésico reacciona con los productos hidratados de cemento produciendo sulfato cálcico e hidróxido de magnesio (Lee, Moon, \& Swamy, 2005). El hidróxido de magnesio (brucita) es un compuesto de baja solubilidad con un $\mathrm{pH}$ de su solución saturada de 10.5 , que provoca la descomposición del C-S-H liberando cal, que a su vez reacciona con el sulfato magnésico formando hidróxido de magnesio y yeso. El hidróxido de magnesio reacciona con los silicatos hidratados liberados en la descomposición del C-S-H propiciando la formación de silicato magnésico hidratado (M-S-H gel) que carece de propiedades cohesivas (Rasheeduzzafar et al., 1994). Por otra parte la formación de brucita tiende a reducir la permeabilidad del hormigón protegiendo capas internas del material (Shah \& Hookham, 1998). La doble capa formada por brucita y yeso, en la zona superficial del hormigón, se va eliminando debido a la pérdida de cohesión entre la zona interna en buen estado y la parte externa deteriorada por el ataque a sulfatos (Lee \& Swamy, 2005). Al-moudi (2002) observó en el caso del sulfato magnésico, que un bajo contenido de hidróxido cálcico incrementa la reacción de los sulfatos con $\mathrm{C}-\mathrm{S}-\mathrm{H}$, generando reblandecimiento de la matriz cementicia, pérdida de masa y reducción de la resistencia a compresión. Las Figuras 2 y 3 muestran los perfiles de penetración del ion sulfato a distintas edades. La mezcla CPRS, a partir de 7,5 $\mathrm{mm}$ de profundidad, presenta un aumento de concentración significativo a 546 días de exposición. En cambio las mezclas que contienen adiciones muestran un sensible descenso en las concentraciones de igual profundidad.

Comparando los perfiles a distintas edades (Figura 4), se observa que a 182 días los frentes de penetración alcanzan en $8,5 \mathrm{~mm}$ el punto de penetración a partir del cual se mantienen valores constantes. En cambio a 546 días, esta condición se sitúa a una distancia de $5 \mathrm{~mm}$ y las concentraciones a profundidades mayores experimentan un sensible descenso respecto a los 182 días, con excepción de la mezcla CPRS. Para los hormigones CPRS+HS y CPRS+CV esto se puede atribuir a la formación de brucita y yeso generada por el $\mathrm{MgSO}_{4}$, la cual impide el suministro de sulfatos provenientes del exterior, provocando una disminución de concentraciones debido a la difusión hacia el interior.

Las Figuras 5 y 6 exponen los perfiles de penetración del ion magnesio. Los resultados obtenidos muestran que el empleo de adiciones minerales no mejora sensiblemente la resistencia del hormigón a la difusión de este agente agresivo. La mayoría de los hormigones presentaron un mismo comportamiento, siendo diferente el hormigón EHA que presentó concentraciones más elevadas a diferentes edades debido a su contenido inicial (Ver Tabla 2). El perfil de todas las muestras a 546 días muestra una alta concentración de magnesio en los primeros $5 \mathrm{~mm}$, pudiendo ser esto debido a la formación de brucita, lo cual coincide con lo mencionado en los perfiles de sulfatos provenientes de $\mathrm{MgSO}_{4}$.
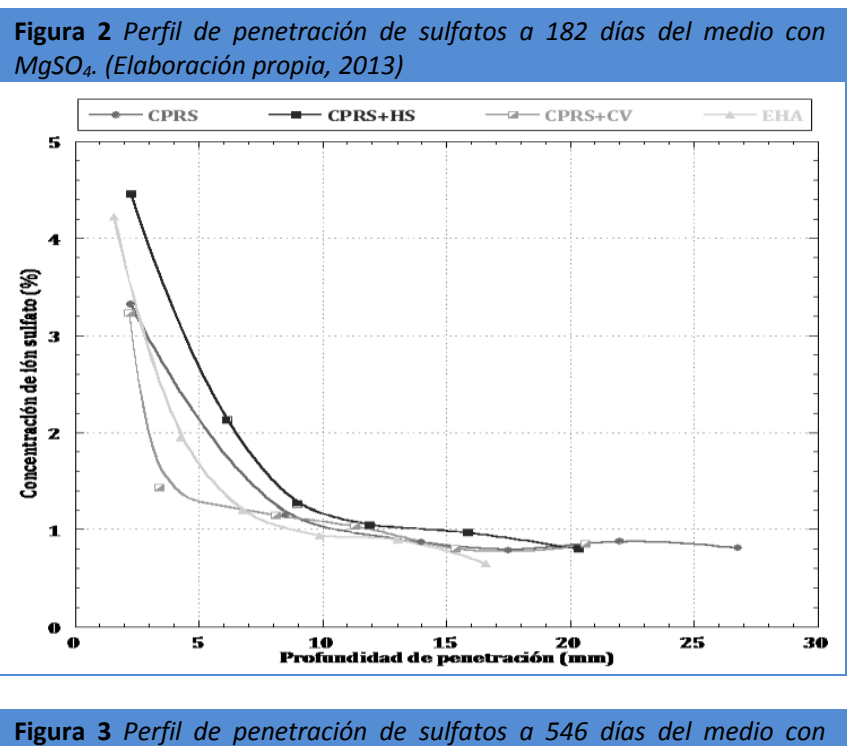
$\mathrm{MgSO}_{4}$. (Elaboración propia, 2013)

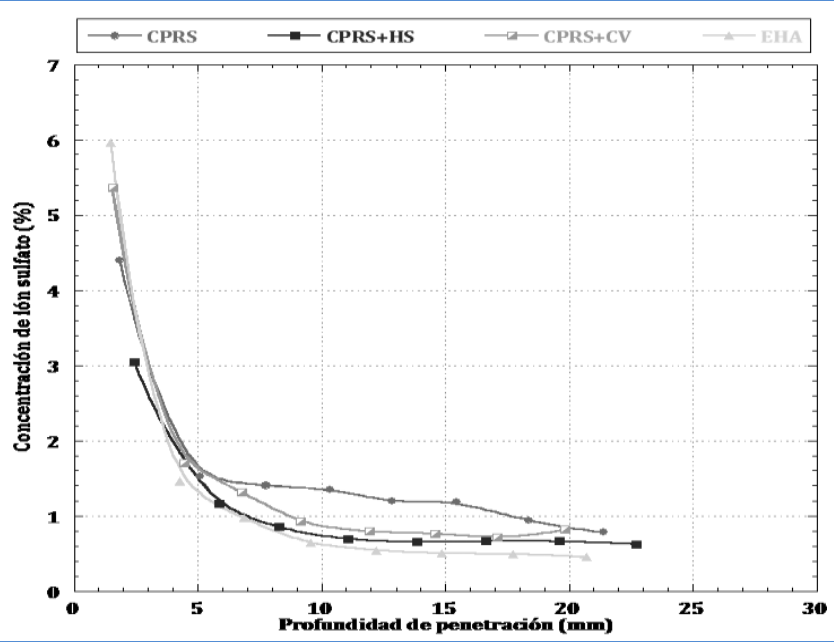


Figura 4 Perfiles de penetración del ion sulfato a distintas edades. Medio con $\mathrm{MgSO}_{4}$. (Elaboración propia, 2013)

a) CPRS

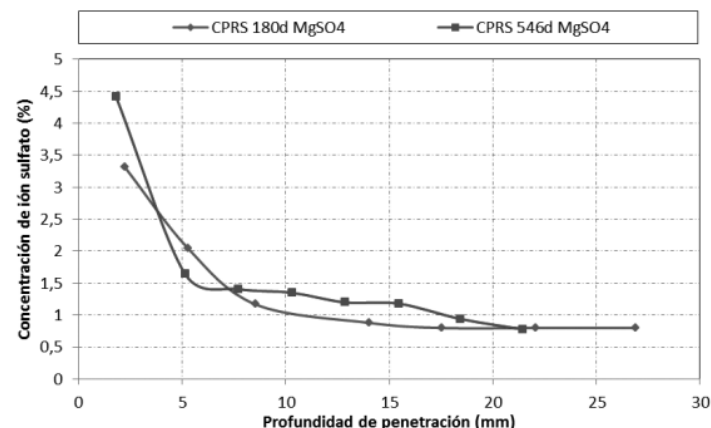

b) $\mathrm{CPRS}+\mathrm{HS}$

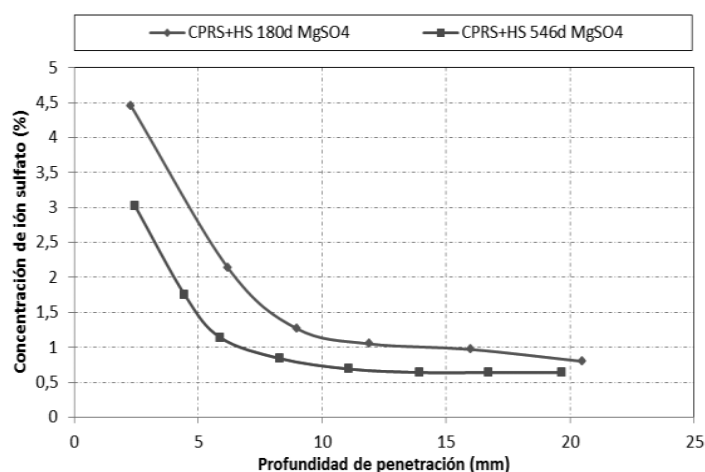

c) $C P R S+C V$

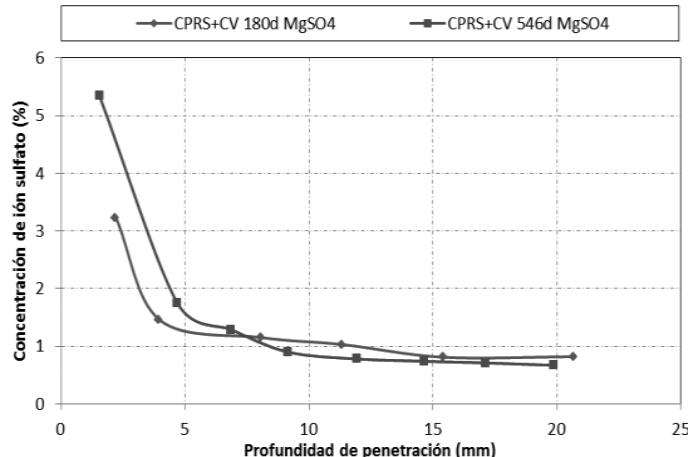

d) EHA

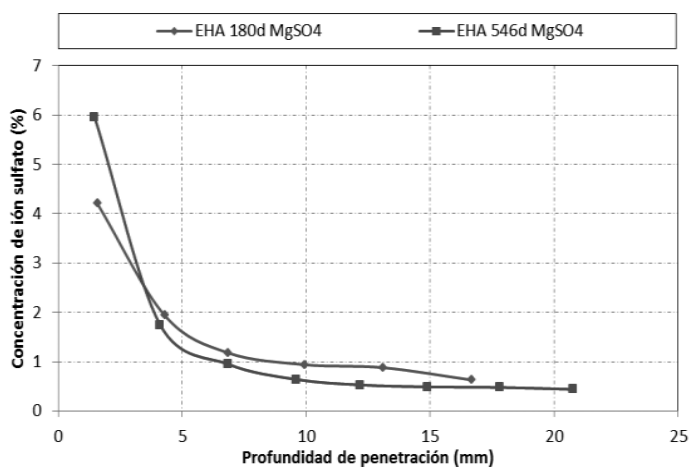

Figura 5 Perfil de penetración del ion magnesio a 182 días del medio con $\mathrm{MgSO}_{4}$. (Elaboración propia, 2013)

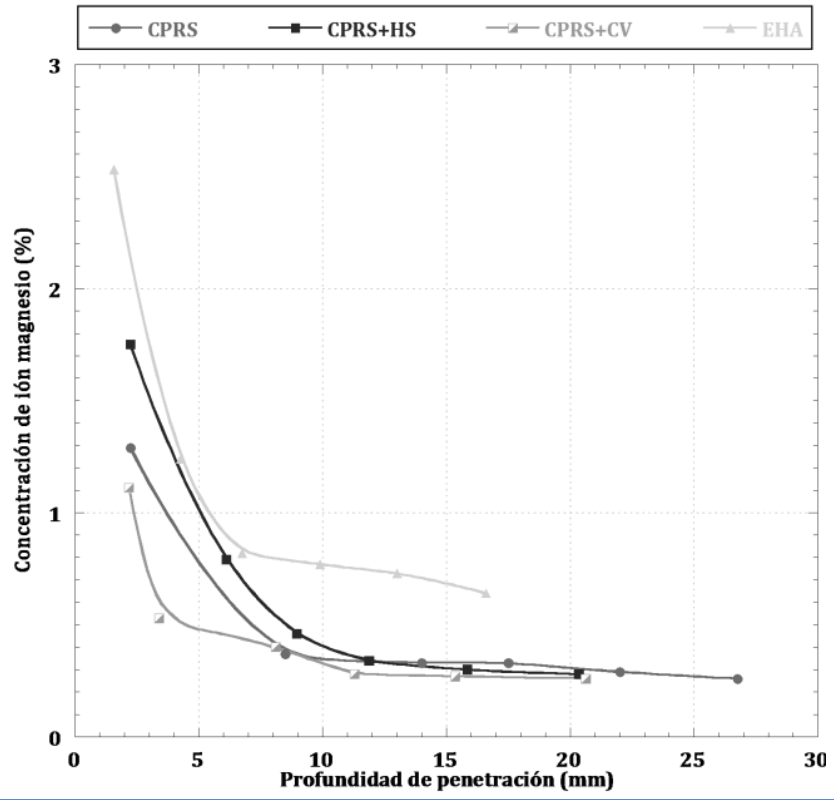

Figura 6 Perfil de penetración del ion magnesio a 546 días del medio con $\mathrm{MgSO}_{4}$. (Elaboración propia, 2013)

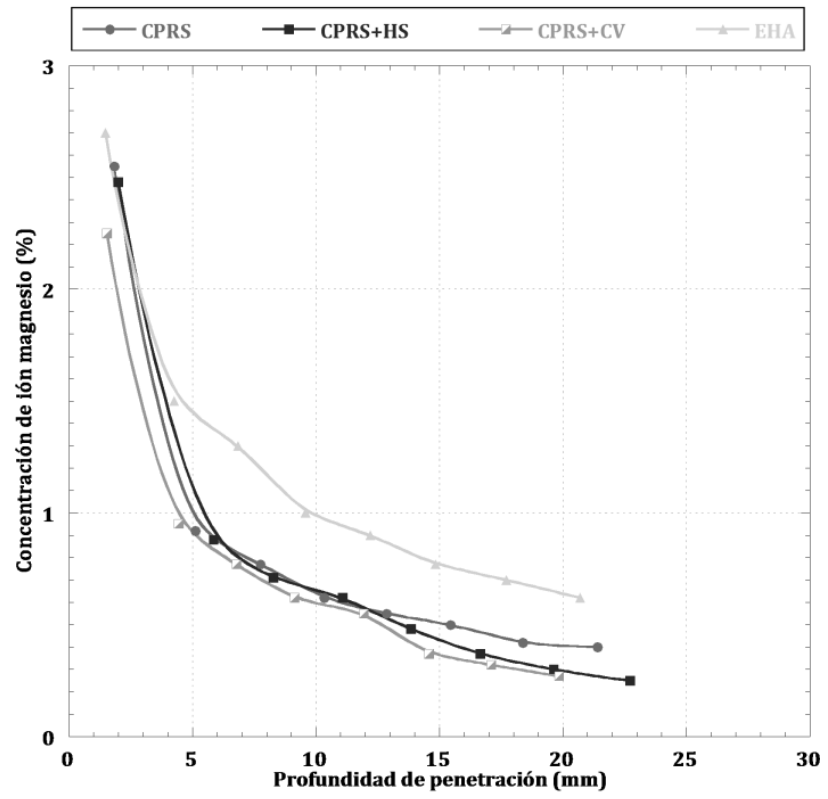


La Figura 7 expone los resultados del ensayo de resistencia a compresión. Se observa que todas las mezclas a excepción de EHA, experimentan una reducción en sus valores a edades mayores. Lo anterior se puede atribuir a la formación de hidróxido de magnesio que provoca la descomposición de C-S-H para dar lugar a M-S-H, un compuesto carente de propiedades cohesivas. La mejora en el comportamiento de EHA puede ser asignado al mayor porcentaje de adición empleado (66-80\%) por el cemento CEM III/B 42,5 L/SR. Una mayor cantidad de escoria disminuye la cantidad de hidróxido cálcico libre en el sistema y evita la formación de hidróxido magnésico. La resistencia de EHA a la agresividad del $\mathrm{Mg}$, se atribuye a las características de los silicatos hidratados formados durante la hidratación. Estos compuestos presentan una estructura química distinta a los $\mathrm{C}-\mathrm{S}-\mathrm{H}$, incorporando Al en las cadenas, lo que impide su descomposición ante un ataque por $\mathrm{Mg}$ y garantiza su resistencia mecánica.

La Figura 8 compara los resultados del ensayo de resistencia a compresión de los hormigones curados en el medio de referencia $\left[\mathrm{Ca}\left(\mathrm{OH}_{2}\right)\right]$ y los expuestos en $\mathrm{MgSO}_{4}$. Las mezclas $\mathrm{CPRS}+\mathrm{CV}$ y $\mathrm{CPRS}+\mathrm{HS}$ expuestas al medio agresivo, presentan valores inferiores que las mezclas de referencia con un descenso aproximado del $25 \%$ y $30 \%$, respectivamente. La dosificación CPRS alcanza resistencias superiores a 182 días, posterior a esa edad evoluciona negativamente experimentando una pérdida del $15 \%$ a 546 días. La mezcla EHA presenta el mejor comportamiento presentando valores claramente superiores en las edades mayores.

Figura 7 Evolución de la resistencia a compresión en medio con $\mathrm{MgSO}_{4}$ (Elaboración propia, 2013)

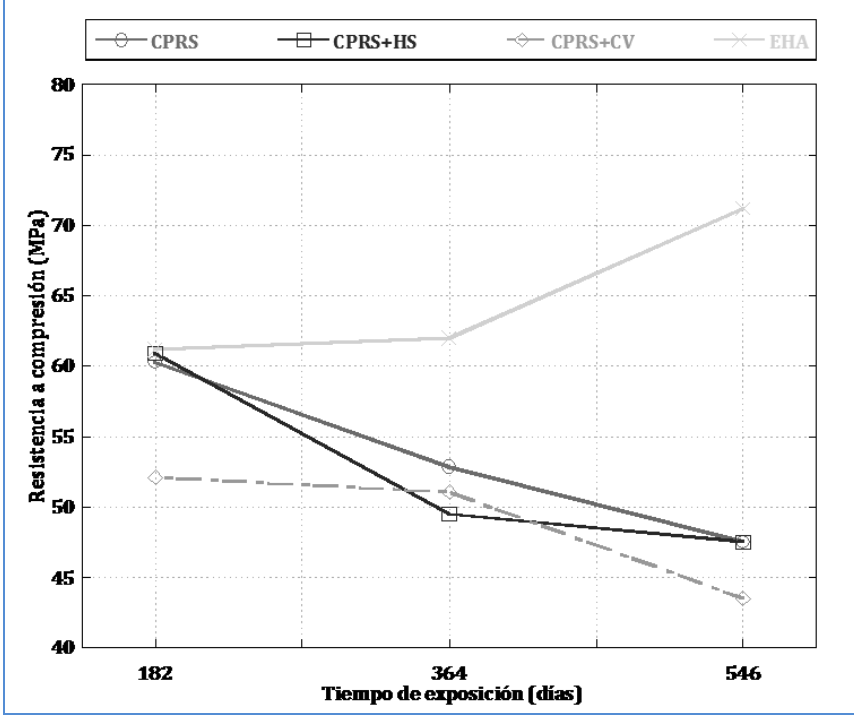

Los resultados de la porosidad de los hormigones expuestos a $\mathrm{MgSO}_{4}$ nos permiten interpretar su influencia en la microestructura del hormigón. En la Figura 9 la mezcla EHA es la que presenta una mayor reducción debido a los mismos factores que propician el aumento de su resistencia a compresión. En cambio, para las mezclas CPRS y CPRS+CV la disminución en la porosidad por la formación de yeso e hidróxido de magnesio cierran poros sin transcendencia en resistencia. Respecto a CPRS+HS se observa un aumento de porosidad considerable, ya que por tener un bajo contenido de hidróxido cálcico se intensifica la descomposición de geles C-SH. La Figura 10 compara los valores de porosidad de los hormigones curados en el medio de referencia $\left[\mathrm{Ca}\left(\mathrm{OH}_{2}\right)\right]$ y los expuestos en $\mathrm{MgSO}_{4}$. Las mezclas CPRS y CPRS+CV presentan una tendencia similar en ambos tipos de ambiente, alcanzando valores de porosidad menores en las muestras expuestas al agresivo. La dosificación CPRS+HS muestra un aumento de porosidad de las muestras localizadas en el medio agresivo a partir de 364 días de exposición. En la mezcla EHA se obtiene una reducción bastante significativa de la porosidad a edades mayores.

La Figura 11 presenta los porcentajes de los rangos de diámetro de poro presentes en las muestras expuestas a $\mathrm{MgSO}_{4}$, así como su porosidad total. Los valores en el rango D2 para las distintas mezclas, oscila alrededor del $90 \%$ de forma similar al de las muestras expuestas a $\mathrm{Na}_{2} \mathrm{SO}_{4}$. Se observa un aumento destacable en la porosidad total de la mezcla CPRS+HS con un incremento considerable en el rango D1 (macroporos).

La Figura 12 muestra los difractogramas de cada uno de los hormigones estudiados sumergidos en sulfato magnésico, distinguiendo entre valores obtenidos en la zona externa e interna de la probeta. En el caso de la mezcla CPRS se analizó únicamente en su zona externa, donde se observó la presencia de yeso en todas las edades, así como el descenso en la cantidad de $\mathrm{Ca}(\mathrm{OH})_{2}$. La presencia de etringita en la dosificación CPRS se observa en todas las edades. A 546 días de exposición se identifica también la presencia de hidróxido de magnesio (brucita).

En la mezcla CPRS+HS no se identifica la presencia de $\mathrm{Ca}(\mathrm{OH})_{2}$ en la zona externa pero sí un alto contenido de yeso. Al no existir reserva de portlandita no es posible la formación de brucita, bajo estas condiciones el $\mathrm{MgSO}_{4}$ centra su ataque en las geles de C-S-H disminuyendo la resistencia mecánica y aumentando la porosidad. Las mezclas CPRS+CV y EHA en su parte interna no presenta grandes cambios en los resultados obtenidos para la diferentes edades, lo cual es compatible con una baja permeabilidad en zonas interiores. Sin embargo el hormigón $\mathrm{CPRS}+\mathrm{CV}$ en su zona externa experimenta la influencia del $\mathrm{MgSO}_{4}$ ya que aparece brucita, aumenta el yeso y disminuye la portlandita. En el caso de la mezcla EHA se observan valores muy similares en capas externas e internas, resaltando con esto su baja permeabilidad y la alta estabilidad química frente al ión magnesio de los compuestos hidratados formados

La Figura 13 muestra los resultados del análisis térmico diferencial realizado en los hormigones para distintas edades, distinguiendo entre valores de zona interna y externa. Los resultados obtenidos en la zona interna no muestran productos obtenidos como consecuencia de la interacción química del sulfato magnésico y la matriz del hormigón, confirmando lo obtenido en Difracción de Rayos X. Los resultados obtenidos en la zona externa de las muestras se muestran más influenciados por el $\mathrm{MgSO}_{4}$. La mezcla CPRS muestra una mayor presencia de yeso, así como la presencia de brucita a 546 días de edad. En la mezcla CPRS+HS se observa un descenso en el gel C-S-H y un aumento de yeso, así como un consumo significativo de $\mathrm{Ca}(\mathrm{OH})_{2}$. En los casos de las mezclas CPRS $+\mathrm{CV}$ y EHA no se aprecian cambios significativos. 
Figura 8 Grafico comparativo de la resistencia a compresión de los hormigones de referencia y los sumergidos a $\mathrm{MgSO}_{4}$ (Elaboración propia, 2013)

a) CPRS

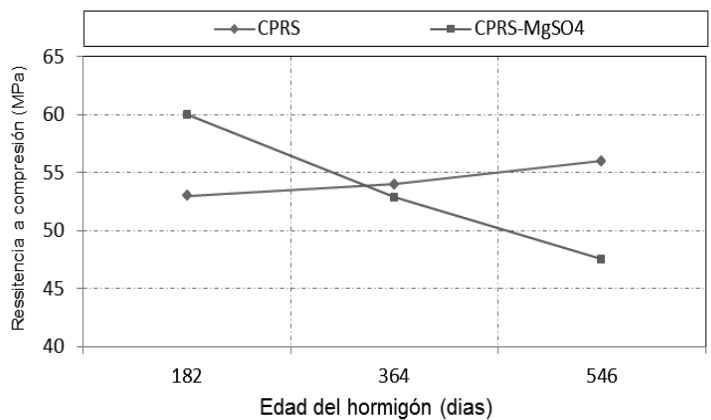

b) CPRS+HS

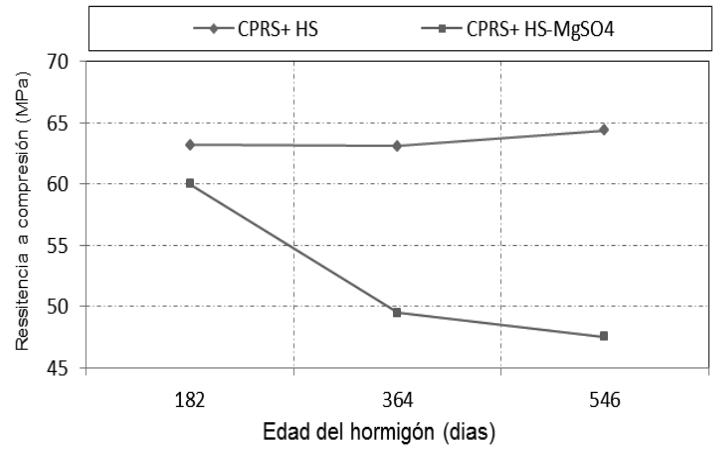

c) $\mathrm{CPRS}+\mathrm{CV}$

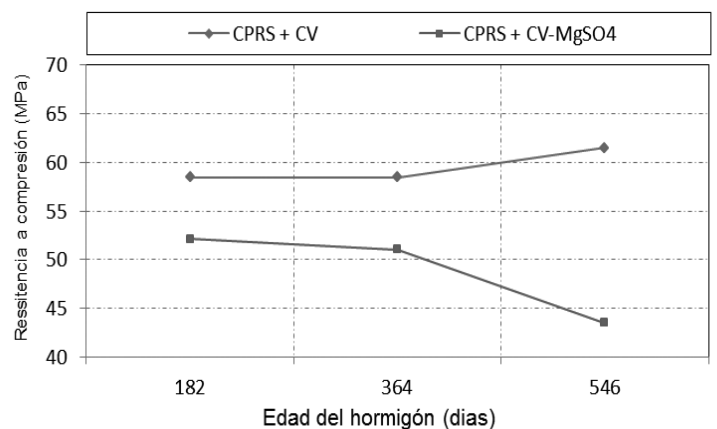

d) EHA

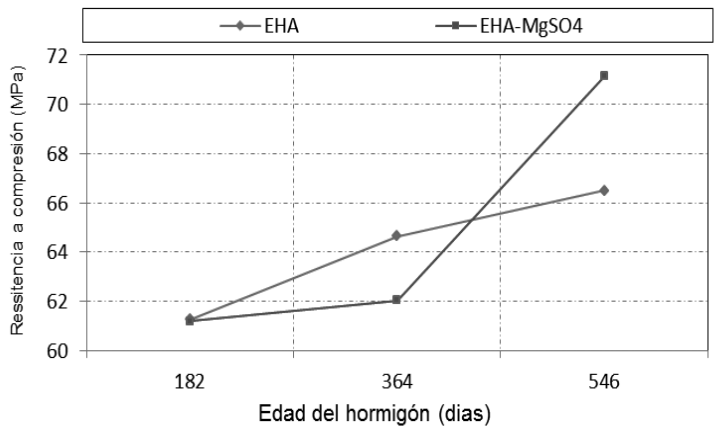

Figura 9 Evolución de la porosidad de los hormigones. Medio con $\mathrm{MgSO}_{4}$ (Elaboración propia, 2013)

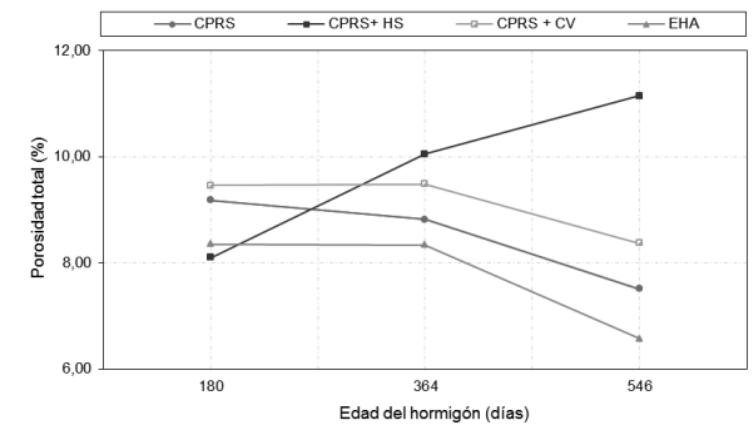

Figura 10. Gráficos comparativos de la porosidad en los hormigones de referencia y los expuestos a $\mathrm{MgSO}_{4}$. (Elaboración propia, 2013) a) CPRS

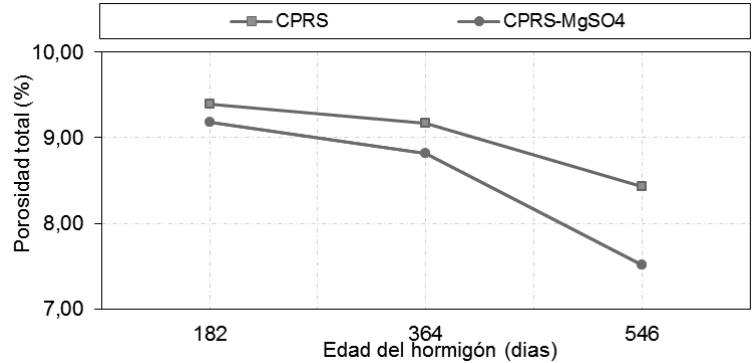

b) $\mathrm{CPRS}+\mathrm{HS}$

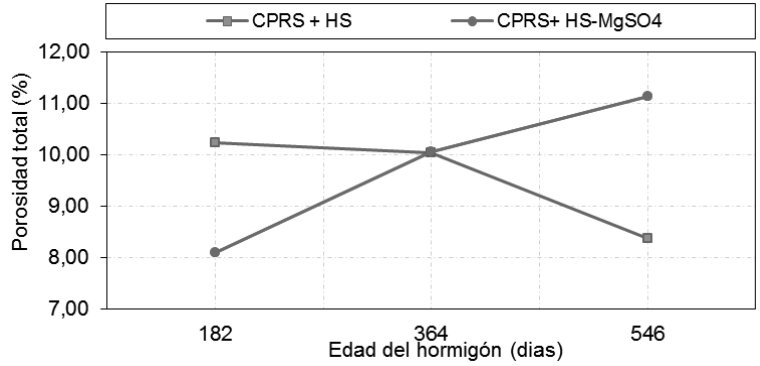

c) $\mathrm{CPRS}+\mathrm{CV}$

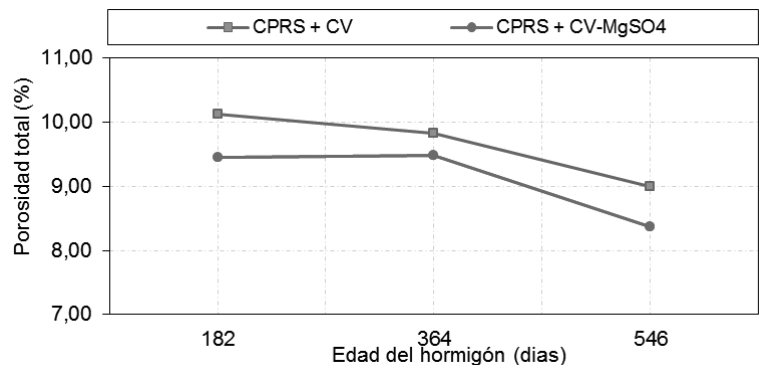

d) EHA

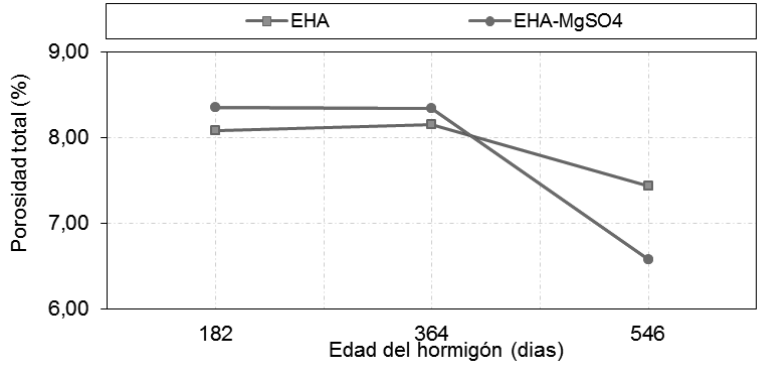




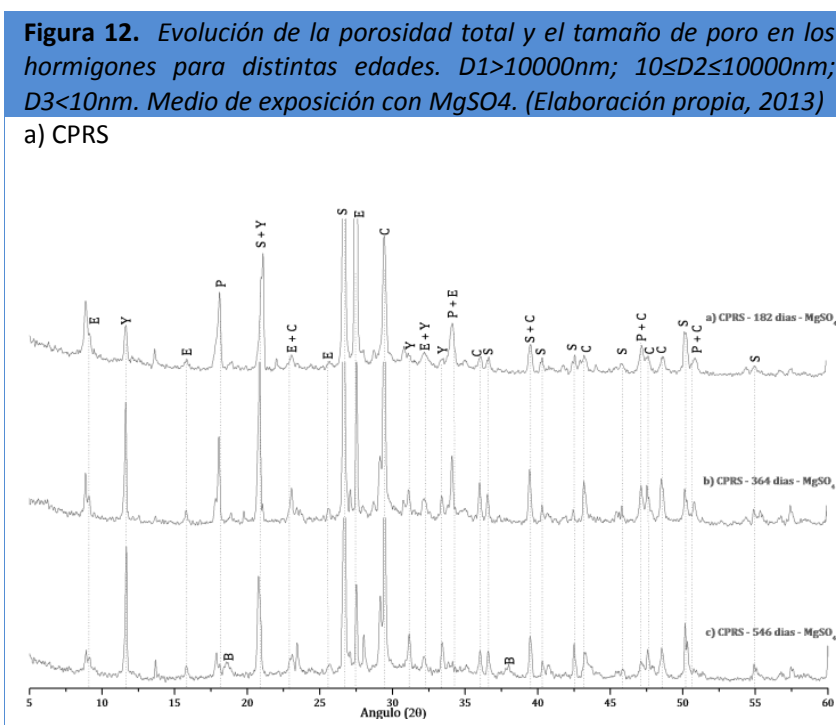

b) $\mathrm{CPRS}+\mathrm{HS}$

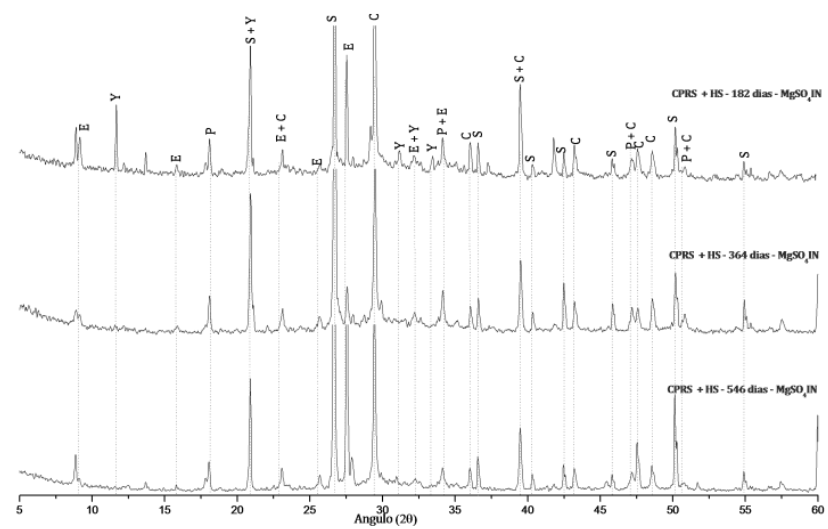

Zona Interna

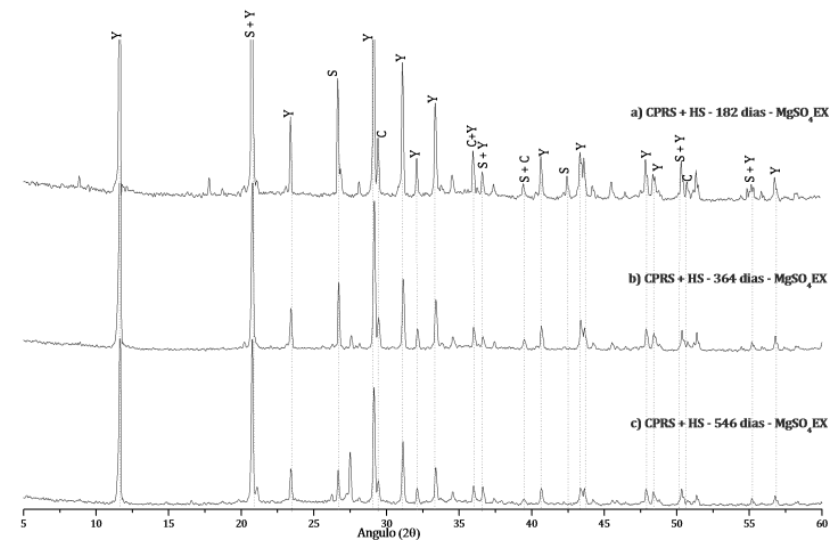

Zona Externa

c) $C P R S+C V$

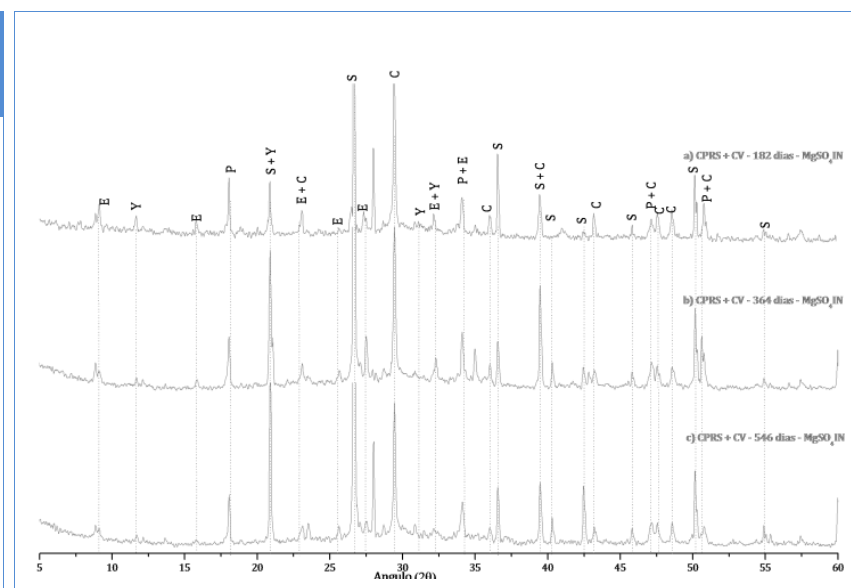

Zona Interna

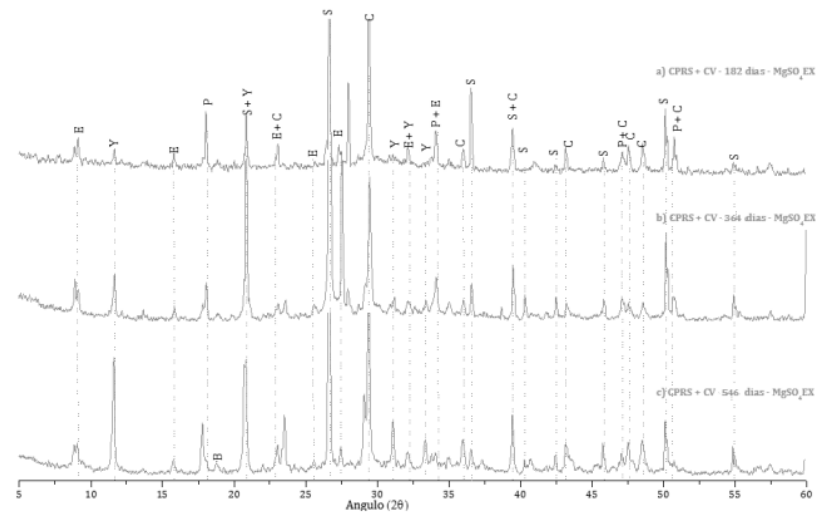

Zona Externa

d) EHA

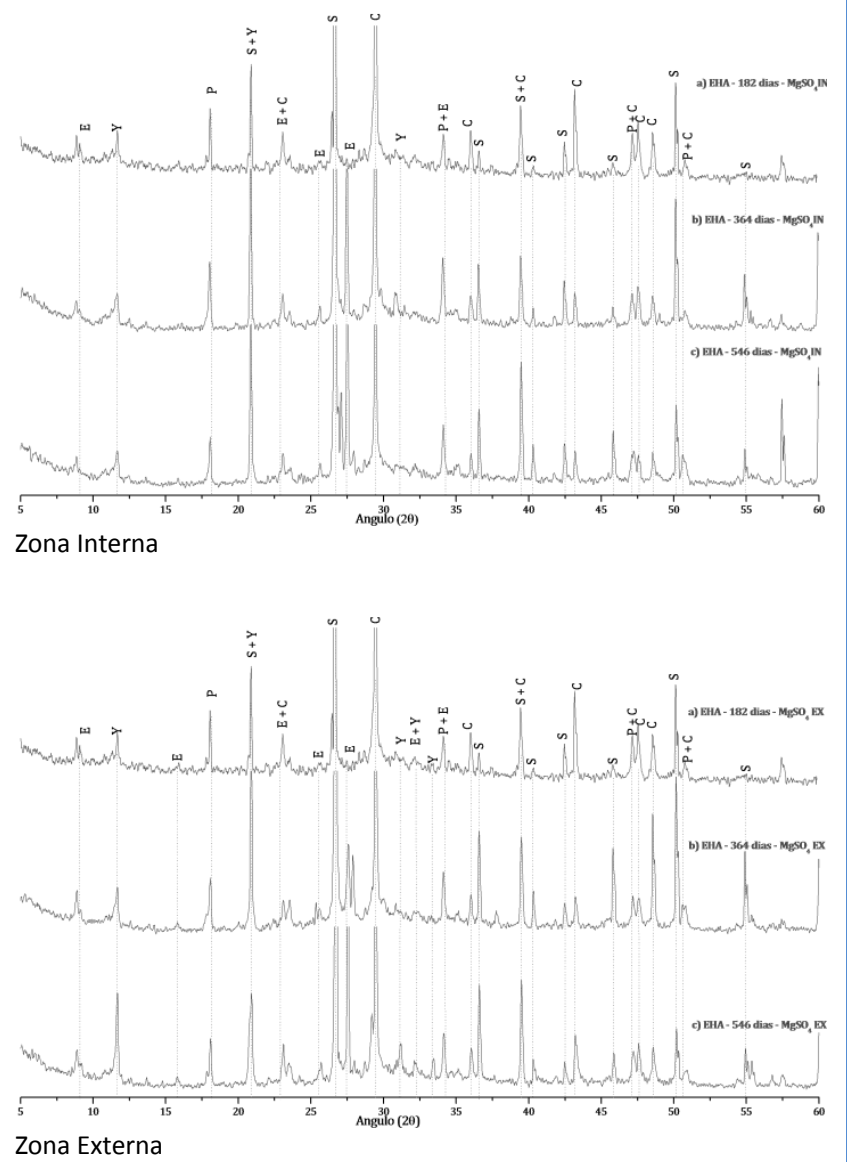


Figura 11. Evolución de la porosidad total y el tamaño de poro en los

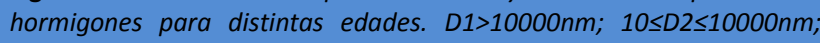
D3<10nm. Medio de exposición con MgSO4. (Elaboración propia, 2013) a) CPRS

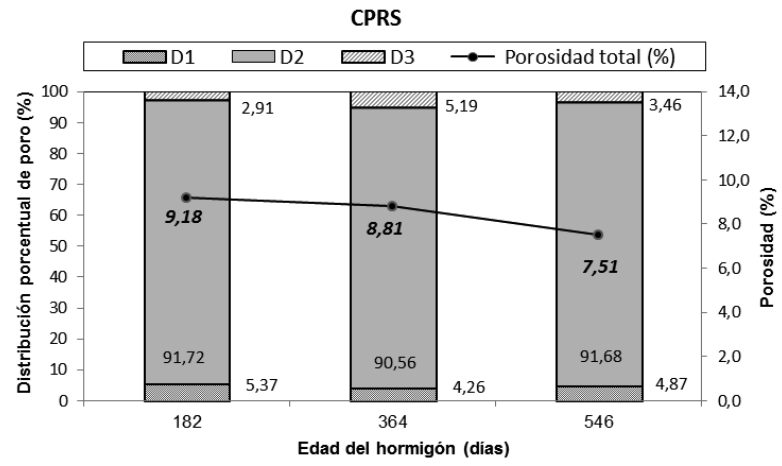

b) CPRS+HS

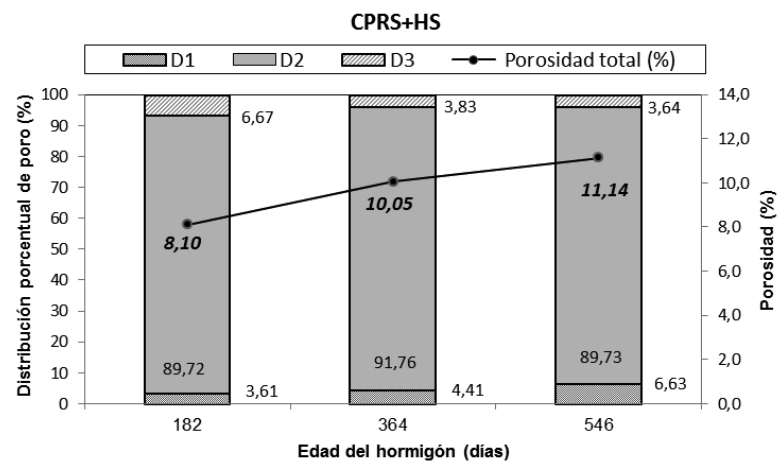

c) $\mathrm{CPRS}+\mathrm{CV}$

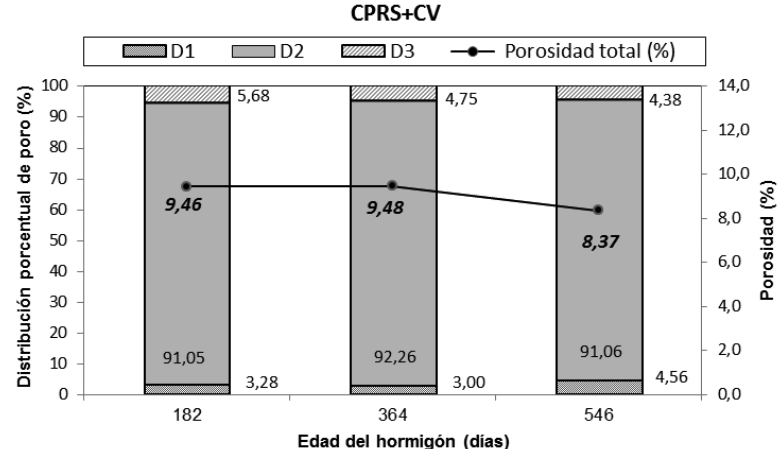

d) EHA

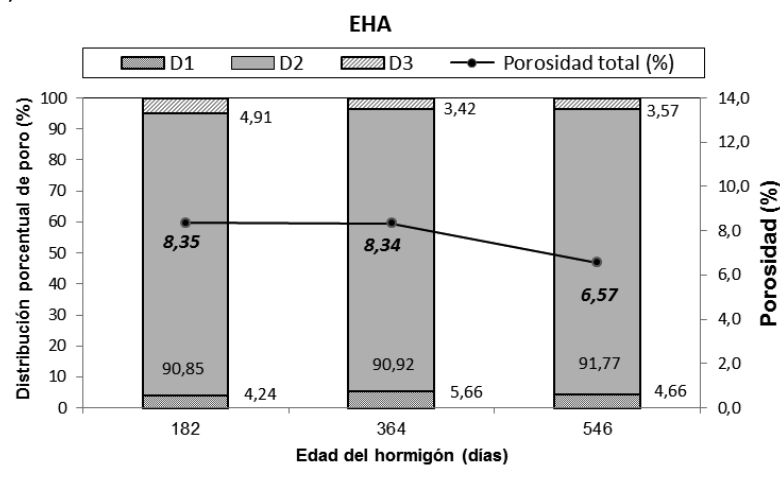

Análisis de perfiles de penetración de sulfatos obtenidos de distintos medios. $\mathrm{Na}_{2} \mathrm{SO}_{4}$ y $\mathrm{MgSO}_{4}$

En la Figura 14 se muestran los perfiles de sulfatos obtenidos en muestras expuestas a sulfato sódico $\left(\mathrm{Na}_{2} \mathrm{SO}_{4}\right)$ y sulfato magnésico $\left(\mathrm{MgSO}_{4}\right)$. Las mezclas CPRS y CPRS+CV presentan resultados similares a 180 días en ambos ambientes. En cambio las correspondientes a CPRS+HS y EHA muestran valores mayores en presencia de $\mathrm{MgSO}_{4}$. Analizando los resultados a 546 días se observan concentraciones mayores en los primeros $5 \mathrm{~mm}$ para las muestras en presencia de $\mathrm{MgSO}_{4}$, exceptuando el caso de la mezcla CPRS, con valores mayores para el ambiente con $\mathrm{Na}_{2} \mathrm{SO}_{4}$.

La Figura 15 compara los valores de los coeficientes de difusión (D) de sulfatos de las distintas mezclas expuestas a $\mathrm{Na}_{2} \mathrm{SO}_{4}$ y $\mathrm{MgSO}_{4}$. Los cálculos se realizaron para 180 y 546 días de exposición. Analizando los resultados se identifican valores de D distintos para cada edad, siendo menores a mayor tiempo de exposición. Lo cual se puede ser debido a la mayor hidratación de las mezclas de hormigón, lo que provoca cambios microestructurales a nivel físico y químico. Por otra parte, se observa que los valores de los coeficientes de difusión para ambas edades son claramente inferiores en las mezclas expuestas a $\mathrm{MgSO}_{4}$. Esto se puede atribuir a la formación de la doble capa de brucita y yeso En el medio de exposición de $\mathrm{Na}_{2} \mathrm{SO}_{4}$ las mezclas EHA y CPRS+CV a 546 días alcanzan los valores más bajos, pudiéndose deber a su activación puzolánica y a los diferentes productos hidratados formados, respectivamente.

\section{Conclusiones}

Los hormigones sumergidos en $\mathrm{MgSO}_{4}$ presentaron formación de brucita y yeso en el primer centímetro de las muestras. Esto se comprobó en los perfiles de sulfato y magnesio, que mostraron una acumulación de ambos agresivos a una misma profundidad. Además de los ensayos microestructurales que identificaron su presencia. Las muestras expuestas a $\mathrm{MgSO}_{4}$ presentaron pérdidas en la resistencia a compresión, con excepción de la mezcla EHA. Estas pérdidas se atribuyen a la alta agresividad del ión magnesio que descompone el gel C-S-H para dar lugar a M-S-H. En cambio la mezcla EHA, al emplear un CEM III/B 42,5 L/SR con gran contenido de escorias de alto horno en su composición, forma silicatos hidratados con una estructura química distinta que ofrecen mayor resistencia al ataque del $\mathrm{Mg}$.

En el medio con presencia de $\mathrm{MgSO}_{4}$ el hormigón $\mathrm{CPRS}+\mathrm{HS}$ experimentó un aumento de porosidad considerable como resultado de la degradación provocada por el ion Mg. En cambio las mezclas CPRS y CPRS+CV redujeron su porosidad, pero no aumentaron su resistencia, lo cual se puede atribuir a la presencia de brucita y yeso, compuestos sin aportación mecánica. La mezcla EHA mantuvo una relación inversa entre resistencia mecánica y porosidad total. En este caso, este comportamiento se puede explicar debido a la continua hidratación de los compuestos del cemento y a su actividad hidráulica y puzolánica con características especiales.

En relación a la composición microestructural de los hormigones expuestos a $\mathrm{MgSO}_{4}$. Las muestras EHA mostraron la presencia de geles con una estructura química distinta al gel $\mathrm{C}-\mathrm{S}-\mathrm{H}$. Esto se comprobó en el análisis térmico diferencial donde se aprecia un desdoblamiento del pico correspondiente a la pérdida de agua de gel, marcando así la distinta composición de los mismos. En los hormigones expuestos a 
$\mathrm{MgSO}_{4}$ los resultados obtenidos de la zona interna de las muestras, no presentan productos como consecuencia de la interacción química del agresivo. Lo cual se puede tener como resultado de la protección brindada por la doble capa de brucita y yeso, que impidió el avance del agresivo. En cambio en la zona externa se presentó una interacción apreciable de los hormigones con el $\mathrm{MgSO}_{4}$, principalmente en la mezcla CPRS+HS, que mostró la mayor degradación física.

La comparación de los perfiles de penetración de sulfatos obtenidos de los distintos medios de exposición $\left(\mathrm{Na}_{2} \mathrm{SO}_{4}\right.$ y $\mathrm{MgSO}_{4}$ ), muestran que la penetración del ion sulfato se ve influida por el tipo de catión que les acompaña. Los perfiles obtenidos en las muestras expuestas a $\mathrm{Na}_{2} \mathrm{SO}_{4}$ presentan valores menores en la parte superficial de la probeta hasta los primeros $5 \mathrm{~mm}$. En cambio, en presencia de $\mathrm{MgSO}_{4}$ se detectaron concentraciones superiores. El cálculo de los coeficientes de difusión de sulfatos presentó valores menores en las muestras expuestas a $\mathrm{MgSO}_{4}$, lo cual se puede atribuir a la presencia de brucita y yeso.

Con base en los resultados obtenidos durante el periodo de tiempo estudiado, se puede afirmar que la presencia de $\mathrm{MgSO}_{4}$ representa un alto grado de agresividad para todas las mezclas, exceptuando el caso de EHA. Los hormigones CPRS, CPRS+CV y $\mathrm{CPRS}+\mathrm{HS}$ con presencia de $\mathrm{MgSO}_{4}$ experimentaron la pérdida de sus propiedades iniciales, con una disminución de sus prestaciones mecánicas y una degradación microestructural. Es importante señalar el buen comportamiento del hormigón EHA elaborado con CEM III/B 42,5 L/SR caracterizado por un alto contenido de escorias de alto horno, que presentó una mejora constante de sus características mecánicas y microestructurales en ambos medios de exposición. Por último cabe destacar que durante la exposición de las muestras a los medios agresivos de $\mathrm{Na}_{2} \mathrm{SO}_{4}$ y $\mathrm{MgSO}_{4}$, los hormigones con adiciones presentaron mayor resistencia a la difusión del ión sulfato debido a la densificación de los materiales.

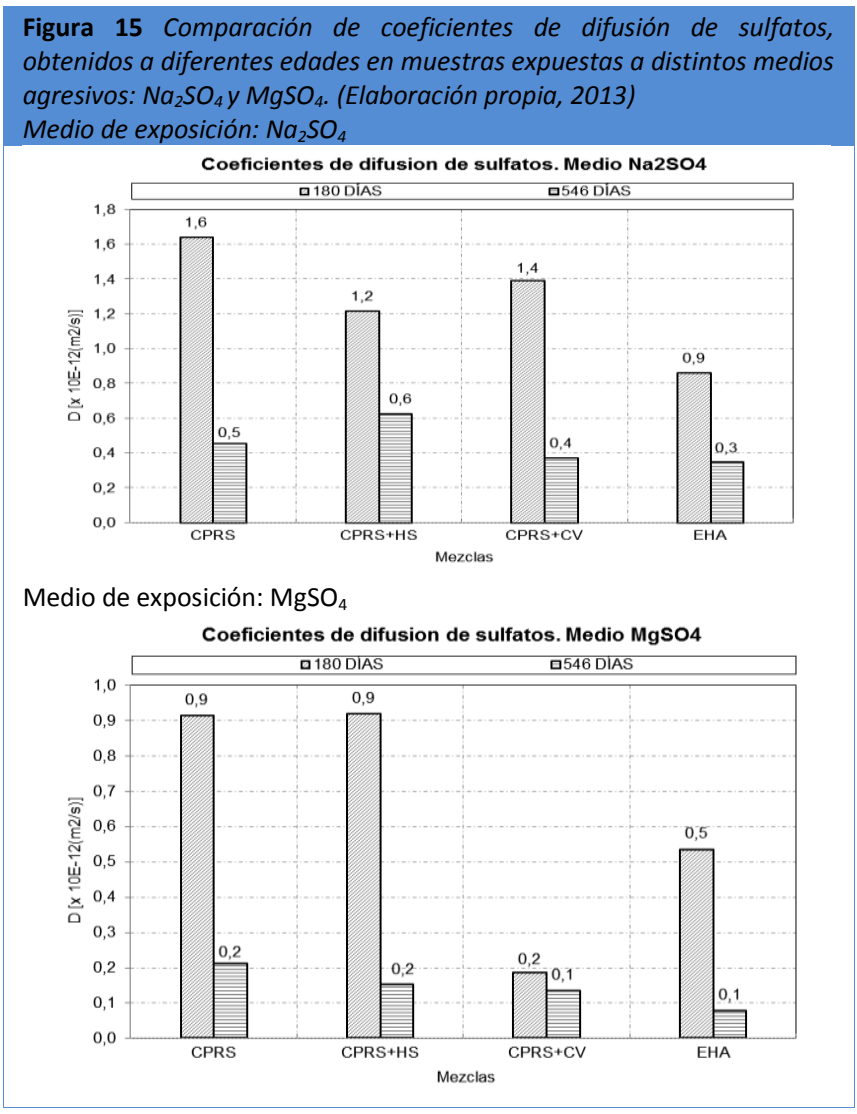

Bibliografía

Al-moudi, O., Maslehuddin, M., \& Saadi, M. (1995). Effect of Magnesium Sulfate and Sodium Sulfate on the Durability Performance of Plain and Blended Cements. ACl Materials Journal, 92 (1), 15-24.

Bernal, J., Mahmoud, S., Reyes, E. \& Moragues, A. (2013). Estudio de la influencia de los medios con presencia de sulfatos en hormigones con cementos sulforresistentes y adiciones minerales. Parte 1: Hormigones expuestos a sulfato sódico (Na2SO4). Revista de la construcción, 12(2), 14-29.

Eglinton, M. (4 ed.) (1998). Lea's Resistance of concrete to destructive agencies. London: P.C. Hewlett.

Lee, S. T., Moon, H. Y., \& Swamy, R. N. (2005). Sulfate attack and role of silica fume in resisting strength loss. Cement and Concrete Composites, 27 (1), 65-76.

Lee, S., \& Swamy, R. (2005). Sulfate attack and role of silica fume in resisting strength loss. Cem and Concr Compos, 27 (1), 65-75.

Metha, P. (1992). Sulfate attack on concrete: A critical review. In Skalny (eds): Materials Science of Concrete III, 105-130.

Neville, A. (2004). The confused world of sulfate attack on concrete. Cement and Concrete Research, 34 (8), 12751296.

Al-Amoudi, O.S.B (2002). Attack on plain and blended cements exposed to aggressive sulfate environments. Cement and Concrete Composites, 24 (3-4), 305-316.

Rasheeduzzafar, O., Al-Amoudi, S., Abduljauwad, M., \& Malehuddin. (1994). Magnesium-Sodium Sulfate Attack in Plain and Blended Cements. ASCE Journal Material Civil Engineering, 6 (2), 201-222.

Shah, V., \& Hookham, C. (1998). Long-term aging of light water reactor concrete containments. Nuclear Engineering and Design, 185 (1), 51-81.

UNE-EN 12390-2:2001. (2001). Ensayos de hormigón endurecido. Parte 2: Fabricación y curado de probetas para ensayos de resistencia. Madrid, España: Asociación Española de Normalización y Certificación (AENOR).

UNE-EN 196-2:2006. (2006). Métodos de ensayo de cementos. Parte 2: Análisis químico de cementos. Madrid, España: Asociación Española de Normalización y Certificación (AENOR).

UNE-EN 197-1:2000. (2000). Cemento. Parte 1: Composición, especificaciones y criterios de conformidad de los cementos comunes. Madrid, España: Asociación Española de Normalización y Certificación (AENOR). 
Figura 13 Análisis térmico diferencial para los hormigones sumergidos en $\mathrm{MgSO}_{4}$ a diferentes tiempos de exposición: a) 182 días b) 364 días c) 546 dias. Se realizaron ensayos en zona interior (IN) y exterior (EX). (Elaboración propia, 2013)

a) CPRS

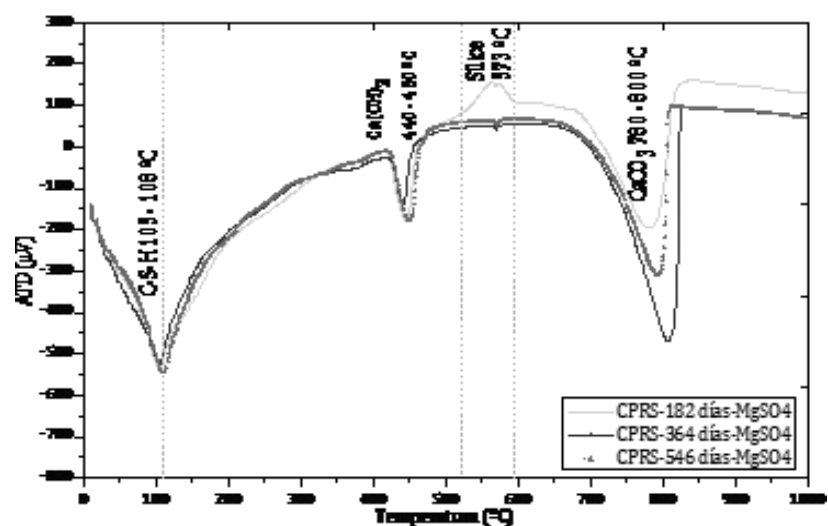

Zona Interna

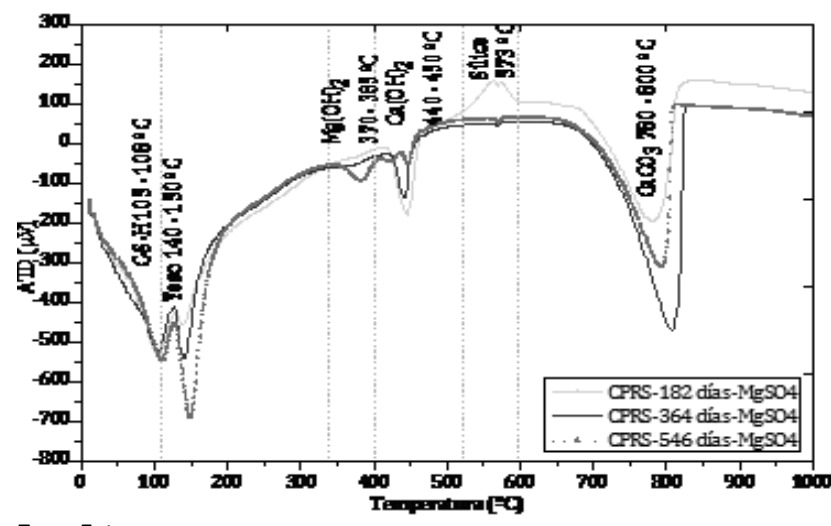

Zona Externa

b) $\mathrm{CPRS}+\mathrm{HS}$

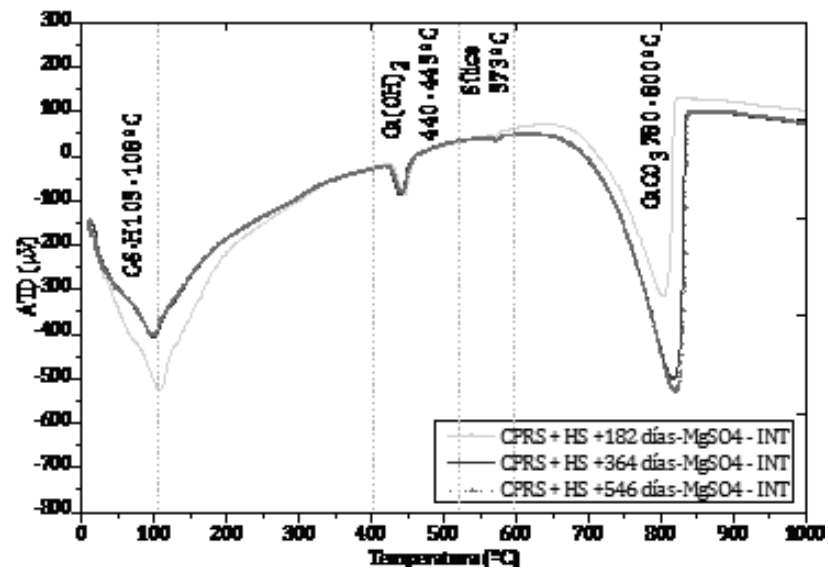

Zona Interna

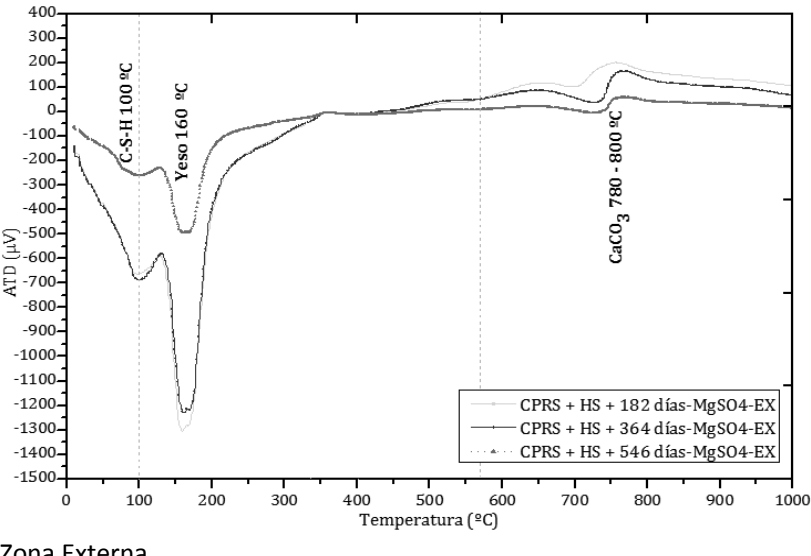

C) $\mathrm{CPRS}+\mathrm{CV}$

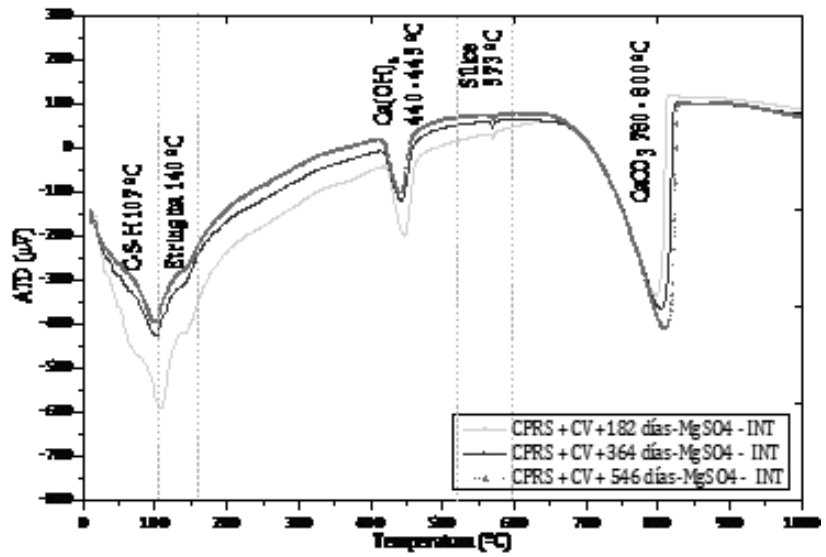

Zona Interna

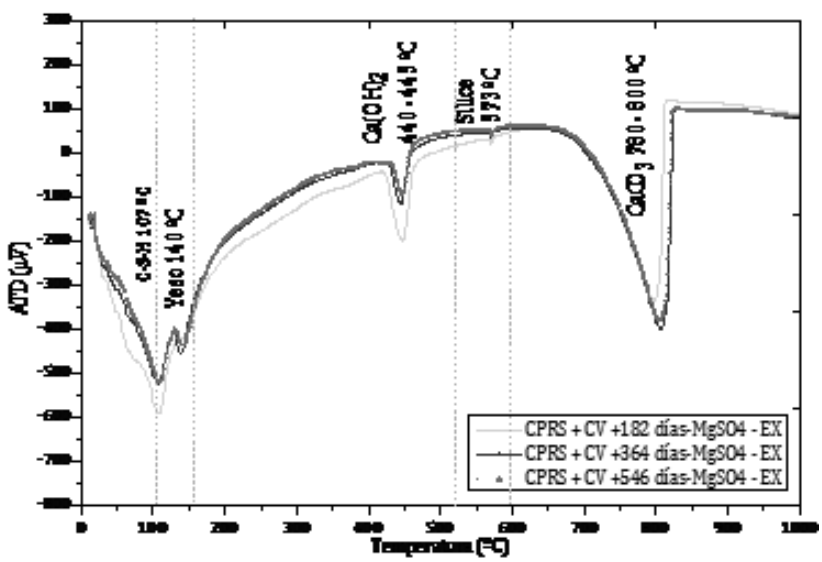

Zona Externa

d) $\mathrm{EHA}$

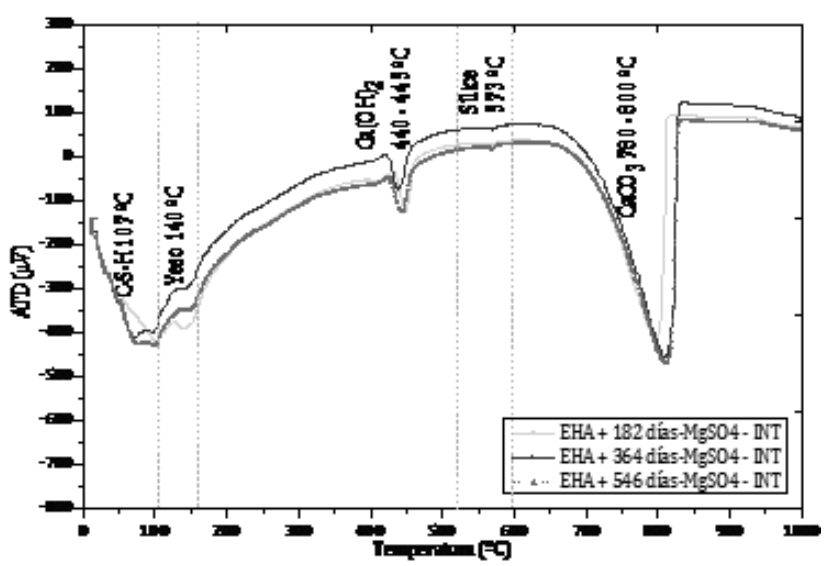

Zona Interna

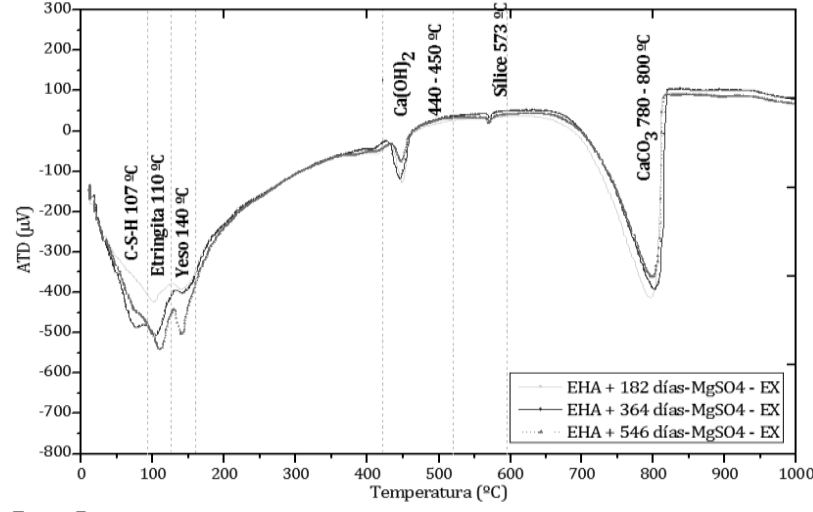

Zona Externa 
Figura 14 Comparación de perfiles de penetración de sulfatos obtenidos a diferentes edades en muestras expuestas a distintos medios agresivos. $\mathrm{Na}_{2} \mathrm{SO}_{4}$ y $\mathrm{MgSO}_{4}$.(Elaboración propia, 2013)

a) CPRS

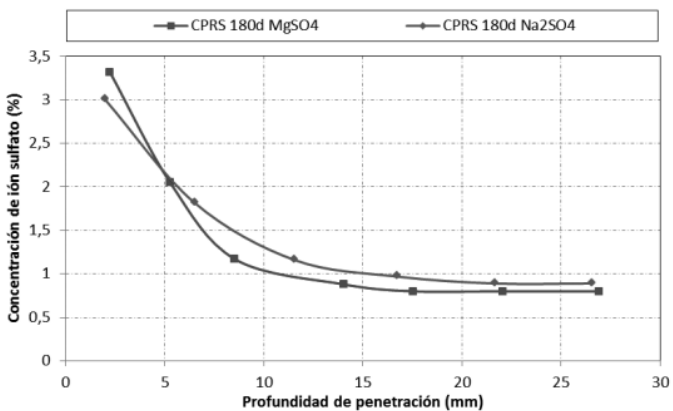

b) $\mathrm{CPRS}+\mathrm{HS}$

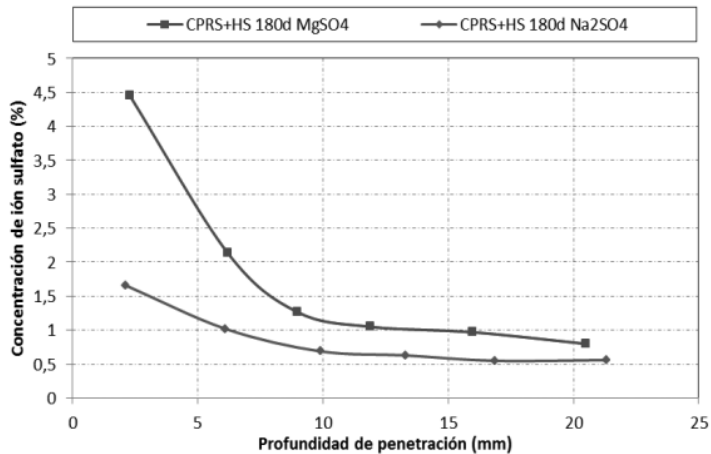

c) $\mathrm{CPRS}+\mathrm{CV}$

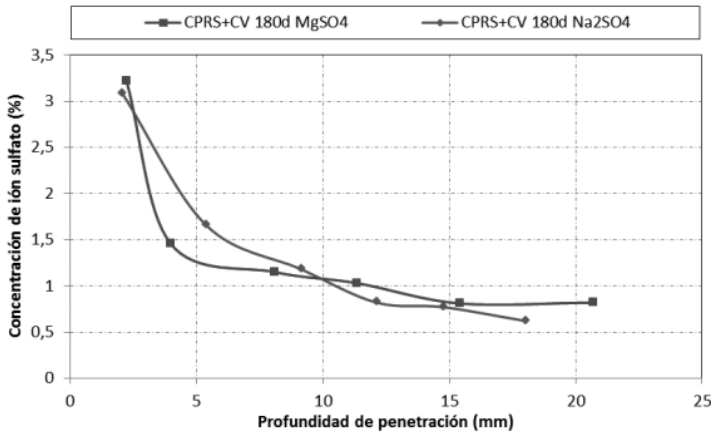

d) EHA

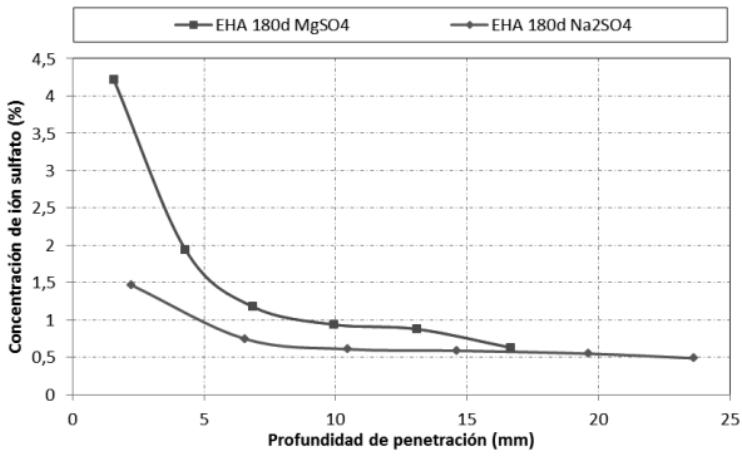

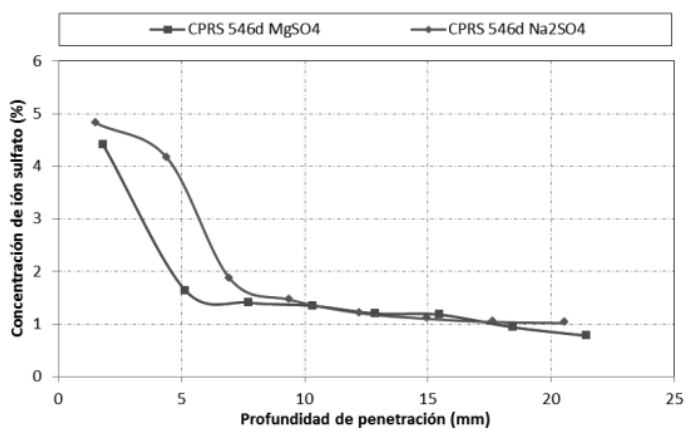
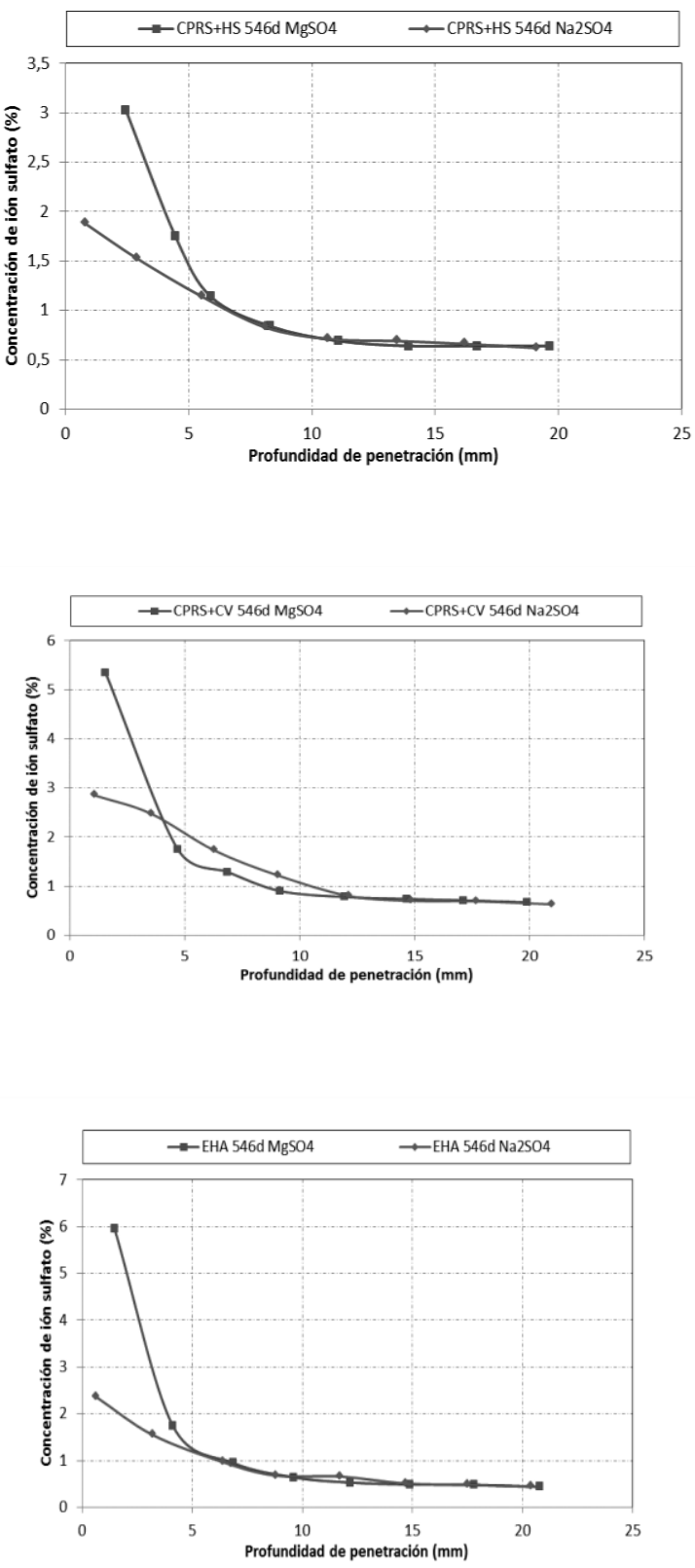